\title{
Using Blockchain in University Management Systems
}

\section{Sura I. Mohammed Ali ${ }^{1}$, Hussien Mohamed Sharaf ${ }^{2}$}

${ }^{1}$ Department of mathematics \&computer applicationCollage of science Al-Muthanna University, Iraq suraibraheem@mu.edu.iq ${ }^{2}$ Department of Computer ScienceFaculty of Computers and Information Suez University, Suez, Egypt H.Sharaf@suezuni.edu.eg

\section{Article History: Received: 11 January 2021; Accepted: 27 February 2021; Published online: 5 April 2021}

\begin{abstract}
Hence, the concept of ledger is easily maintained. Transactions and interactions that take place among participants accessing the distributed and decentralized blockchain network are holding through ledger. In a student management system (SMS), vital information can be highly shared and well protected at the same time. This paper proposes a model for using blockchains to implement fully functional SMS that maintains students' records, course registrations record and student marks. The proposed model adds more security via the use of hashing and data readily available with decentralized data storage. In addition, the use of ledgerbased system to maintain SMS data introduces reliable and highly trusted model.
\end{abstract}

Keywords: UniversityManagement System,Blockchain, student's records

\section{Introduction}

Education is a corearea where development takes place on different levels of education.

Regardless of the marked enchantment in technology, there is nonetheless a desire for creating human recourses via learning, and blockchain makes this easier to achieve. Blockchain can be implemented within the automated management systems of individual higher education institutions or groups of educational institution[1].In education sections, critical of Students' information are vital plus sensitive and to retrieval data of general administrative framework, learning and research may time consuming that cased very problematic[2]. In conventional education framework, there is some of the challenges are recordkeeping. For recordkeeping, blockchain technology gives a protected archive of such records, time-stepped can be a big assist for all stakeholders[3].

Blockchain technology is one of the famous popular techniques in the latest few years[3].One of the most important applications is securing data of student management systems (SMS). The features of blockchain are readiness of sharing and visibility that are essential for any SMS. The entering courses registrations and entering marks can be viewed as transactions similar to financial transitions; once committed to the system must never be removed. A transaction can only be reversed by submitting another reverse transaction.

In the context of blockchains, data is stored in the formsequence of blocks and every block is related to the forming next chainof records and store all committed transactions using a public ledger[4]. Transactions and interactions that take place among participants accessing the distributed and decentralized blockchain network are holding through ledger. In SMS, a transaction could be:

A) An admin: Adding or modifying a student's records.

B) A student/admin: Adding or modifying course registration record.

C) A faculty member: Adding or modifying registration marks (Final exam, MidTerm, course work).

The chain expands continuously when new blocks appended to it. Each blockincludes message, current hash, previous block hash, date; block id, etc. relying on the application[1].

The first block in the blockchain is called genesis block which has no parent, shows in Figure 1.

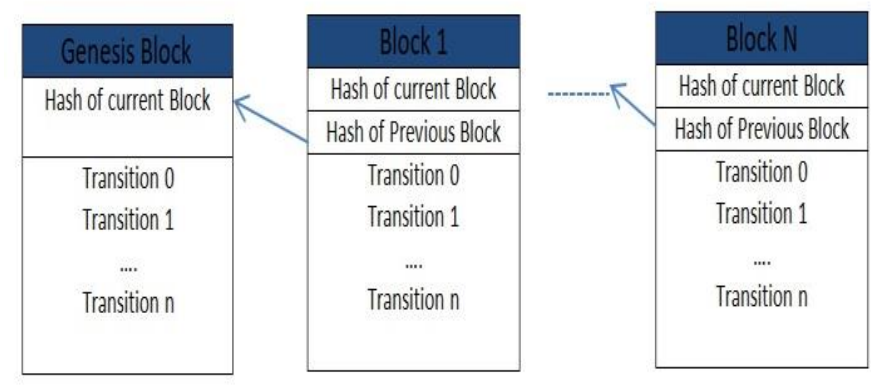

Figure1: The architecture of the blockchain 
All regular transactions rely onthecentralized consensus depending on the party.This offers many interesting features such asdecreasing transaction cost, efficiency, and security. To attain secure, fast and clean transactions, the idea of blockchains will be introduced. A blockchain system processes the transactions submitted by individuals without the need for third party intervention services.

Different approaches have been presented in the domain of student management systems (SMS).

In university context, a lot of efforts and costs are put into managing recordsfor all educational transactionsoccurring since the first-time students submit their papers and register courses for the first semester until they graduate. In this context, appeared of challenges are in all transaction[5].

One of the motivations for this paper is to address how student data should be collected, stored and later accessed. This paper proposesan approach for using blockchain to implement fully functional SMS that maintains students' records, course registrations record and student marks.

The proposed model adds more securityvia the use of hashing and data readily available with decentralized data storage. The information of blockchain that provided by the university is open to all parties that interest it.because of immutability, sensitiveness, and deal with of storing the records in blockchain, helped to get good implementation of student management system [6].In the blockchain can record all values that include birth certificates, social security cards, student loans,etc. through expressed as cod it[6].

\section{How Blockchain Works:}

A blockchain is sequence of blocks that contains setdata. Each block has a cryptographic hash of the previous block and transaction data and stores those transactions in a cryptographically secured data unit called "Blocks".

\subsection{The componentsof blockchain:}

2.2

- Node - it represented as user or computer through blockchain.

- Block - it is network of list nodes including a set of transactions in a particular order distributed on all nodes. the structures of blockchain include on:

$\checkmark \quad$ Pointers - variables that stores index information to another location of variable.

- $\quad$ Linked lists - a series of blocks by a pointer every block links to the next block. Genesis block is called on the first block in the blockchain, which has no parent.

- $\quad$ Transaction - allowed sharing and exchange of information between nodes [7], that requested by a node, and by means of files containing transfer information between nodes. The blockchain updates it status after each transaction.

- Chain - it means a list of blocksin a specific order.

- Consensus - to execute operations of blockchain, it is through a combination of rules and arrangements. it is the most important step in the blockchain process to add his block to the blockchain in the following step:

1) The hash code of a valid block is calculated as in Equation 1[8]. To generate hashing values that through using a mathematical functionagainst tampering.

BHC $=$ Hash $(T D+P+$ Nonce $)$....(1)

Where 'BHC' is the Block Hash Code, 'TD' is the transaction Data, ' $\mathrm{P}$ ' is the hash code of the previous block in the chain, 'Nonce' (Number only once) is an arbitrary number that can be used only once for producing the corresponding $\mathrm{BHC}$.

2) This process is done by solving a complex mathematical algorithm that associated with miner block; this process is called block mining. By calculating a cryptographic block hash, a process of block mining finds the next veracious block.

Miners - in this step, each miner starts to form his block (i.e. a nominated informal block) which involves his selected transactions. At this moment, the selected transactions in the formed block still unconfirmed, since the miner should check the validity of the selected transactions.For exampleif a transaction occurs (Add New Block) from A, it must be verified of transaction with other public records of data by the participants (B, C, D, and F) through copying of data their own.After the verified the transaction, if it is valid, all peers will confirm and accept its validity and approve that the new block can be inserted and updated state of blockchain when added block completed. 


\section{Blockchain for Universities:}

In the education domain, several blockchain technologiesrecently are used. The authors [9] discussed in their paper was that universities Nicosia and Birmingham research center have used Blockcert system. A Blockcert system approves control to issue personal official documents, academic certificates and private data. The Universities of Nicosia and Woolf primarily based on blockchain architecture. A diagram of Blockcert system is shown in figure 2 , it consist of many components that interconnections it of educational environment

Figure 2: Blockcert system[9].

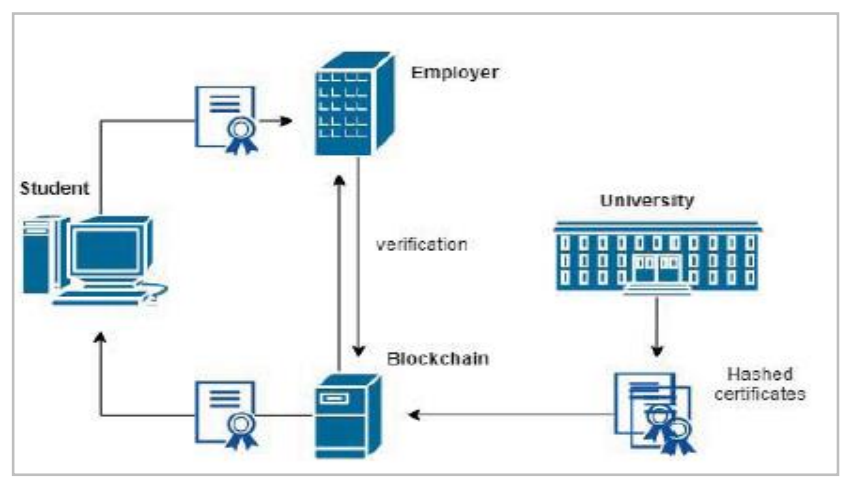

The component of university adds hashed certificates to the blockchain to issues students' diplomas. The component of employers can be verified students' diplomas and search in this blockchain.

The authors [7] discussed in their paper was that 24 universities in Jakarta have used existing McRhys model. McRhys is a model to record and integrate all activities in university using blockchain concept.

"Distributed Open Ledger" is concept that confirm by McRhys model. Information of blockchain can be access by all Participants of the same interest that provided it by the university, also in this model a transaction validated verified before inserted it[5].McRhys Blockchain Model for University in Indonesia system shows in figure 3. The objective of this model is to solve the problems: validity, transparency, reliability of data and access of data with ease by the employer when the concept of blockchain is applied.

The next section discusses the varietyblockchain models that using in the universities. Diploma certificate forgery on university is important problem that focuses it researchers, to solve this problem which is an important contemporary issue therefore is used a term of university blockchain. Another challenge in education institutions; is data record of immutable grades.

Figure 3.McRhys Blockchain Model [7].

Recorded grades should be unchangeable andsaved on a ledger-based system. Once a set of grades are recorded (added transaction), no one is allowed to modify and delete. As a topic within academic circle, we proposed blockchain model for university level to implement fully functional to store the student information and marks as student management systemin form of blocks.

The authors in [10]proposed a new framework based on blockchain. In Figure4, records of education and components added to the system, and then posted to the blockchain to appear it all parties.

Figure 4: Architecture of the Proposed Framework[10]

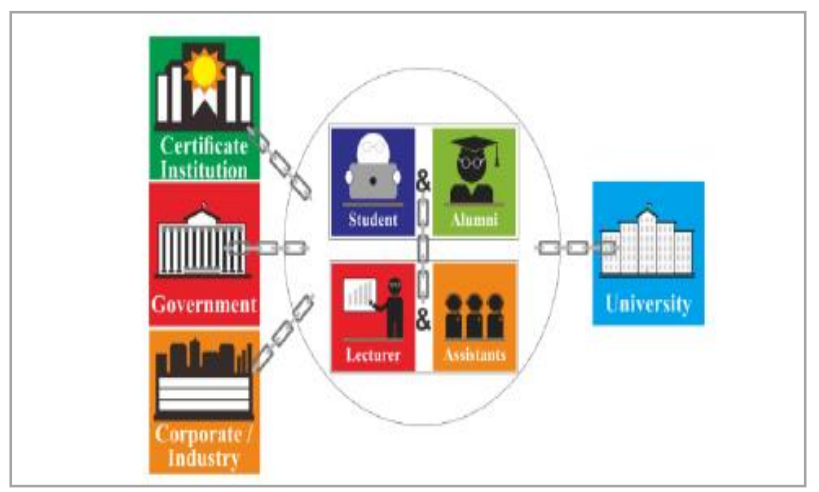


The center of the framework includes individual node, the miner around the blockchain, and the provider node.Proposed framework contribute with provide the blockchain provide the privacy and security of data stored on it, and functions customized access to different parties that corresponding for the education.

\section{Proposed Model Design}

To share, verify, and learningachievements [1], a novel infrastructure of Blockchain technology is ideal for purpose..In this paper, we propose blockchain model for university level to implement fully functional student management system shown in figure 5. We choose to focus on student marks. These are at the core of education area. The model is a workable prototype built to discuss the potential of blockchain for this area. It is a model to record and manage all activities in a university using blockchain concept implemented as a ledger-based system. Each block can be store records of student and their hashthen it will use roles to retrieve original information.

The information hashed in the blockchains; when carried the change in content of one block will invalidate the entire chain of blocks [11]. Each block consist of nonce, header, hash code of the previous block, hash value and time stamp, and each model different from application to another. The model shows data records and interaction of all participants in the model.

Our model has the following functions as three cases. In all cases, both the student and the professor are required to be registered on the course. Figures $(4,5)$ are illustrating these models using activity diagram.

In figure 4, a new blockchain addressgenerates for the student,when students enroll into the course the administration issues a student ID and send these information to the student.Administration stores information (Student ID, Enrolled course of the student, Subject information) about student into itscentralized database.In figure 5 professor registration is almost the same as student.

$>$ Model 1:

Professors and admins are parties of blockchain, when a student registered in the course the first block or "Genesis Block" generated and all parties can access the new student after registration. The model stores enrollment data of student course, their marks (MidTerm mark, Coursework mark, Final Exam) for each semester in one blockchain. Usually, the respective authority runs the mid-term exam and the final exam, for sake of evaluation process. After enrollment the examination, professors input the student mark on the blockchain created.

The control committee of university will receive the report of the marks and test results every semester. This process will be repeated every semester.

At the next stage, the respective authority units publish all students' marks. This result determines the students'fitness status to receive certificates, grade copy and every student receives a unique code printed on the certificate.In figure 6, the student record of marks can be added to the model and posted to the blockchain, professors can do transaction to student accounts for assigning mark for his/her subject. On the other side, students can see their marks on different courses. Students' grades are in their academic year.

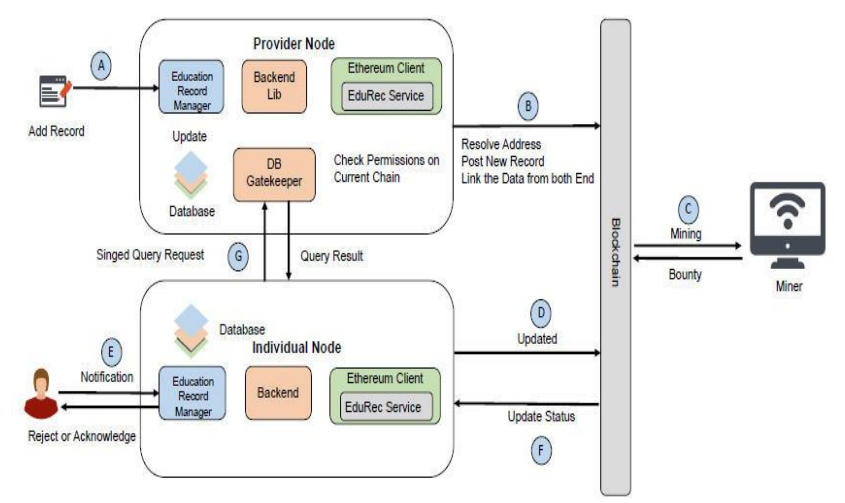




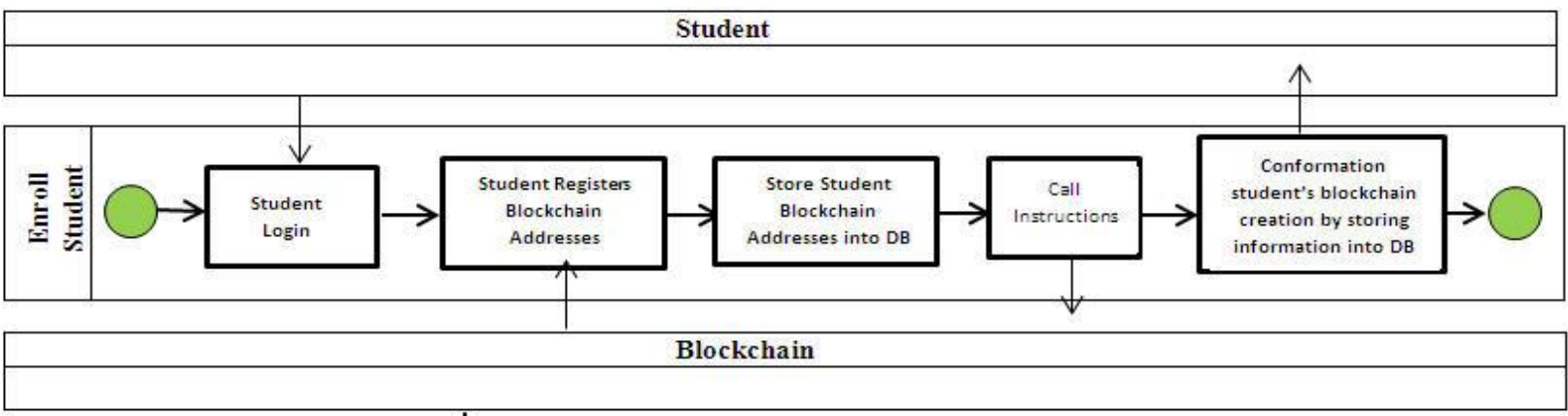

Figure 4: Student registers for the course

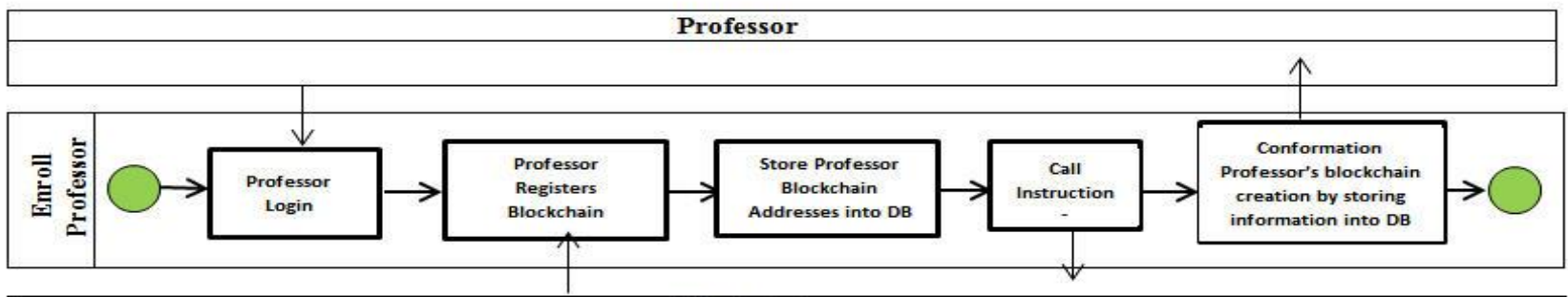

Blockchain

Figure 5: Professor registers for the subjects of course

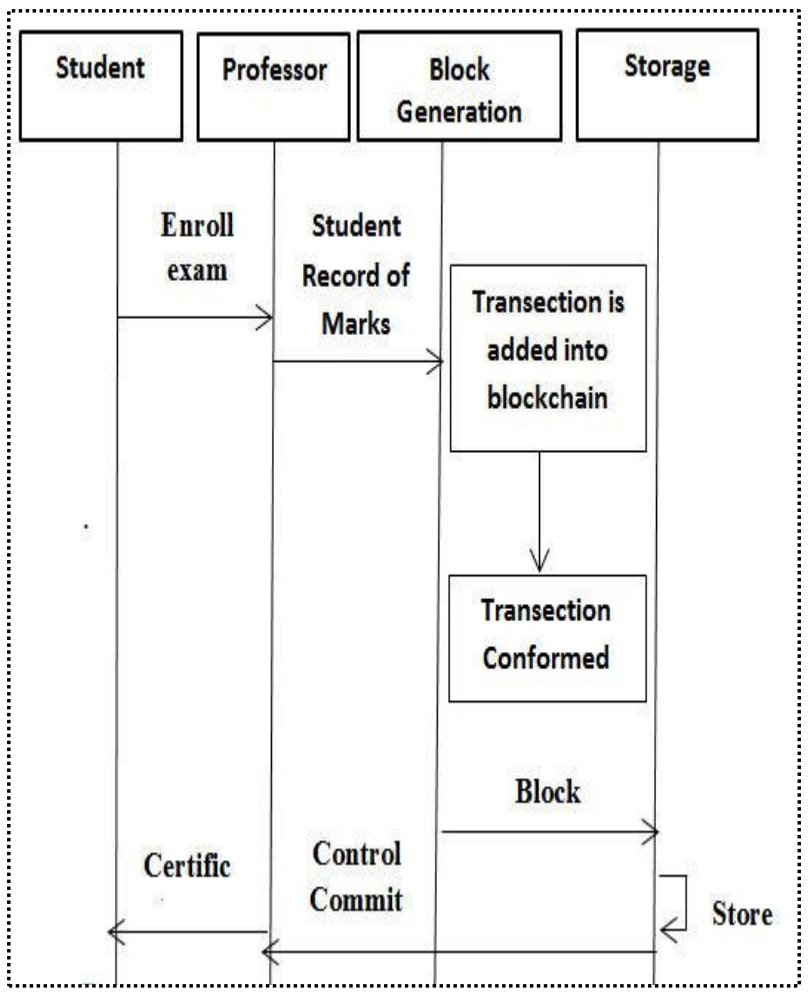

Figure.6 Diagram for storing blocks of marks in blockchain

A studentget notified it once there is any particular update in his block. By a student takes an exam, the professor should verify the results and sends it to the students blockchain address. The transaction is processed through the transaction is confirmed; the information about the grade will be saved into the ledger-based system. On the other side, students can see their grades on subjects of course. 
A unique course symbol for each course in each semester, would allow differentiating between duplicate enrollments in different semesters. The number of transactions is dependent on the number of courses and students in order to transact marks for students. All the transaction information will be stored in the blockchain model. It will not be possible to modify or delete any item.

\section{$>$ Model 2:}

When students enroll into the model, the

administration of the university issues a student ID and generates a new blockchain address for the student. Administration stores following information about student (name, phone, address, ID, social security number) into her/his blockchain address, and stores student course enrollment data in separate blockchain(Marks blockchain).After a student takes an exam, professor sends result to the students blockchain address.

The mark will be saved into central database. On the other side, students can see their marks blockchain that includes their marks on subjects. The control committee inputs ID student into the model as one of the requirements to take it exam in the final semester.Figure 7 illustrates a process model of the above scenario.

Model 3:

The model stores each transaction and $\log$ s the information of the student plus the registration data of course in one blockchain. All transaction will be record into the blockchain such as examination, courses, lecturer, and marks after process of registered completed of student, all of the transactions are inserting in one of blockchain. All updates and additions that be logged will be posted to all related persons.

In this case, the student registration mechanism will be responsible for verifying the courses schedule provided by the university. Therefore, the blockchain transaction list can produce marking list document.

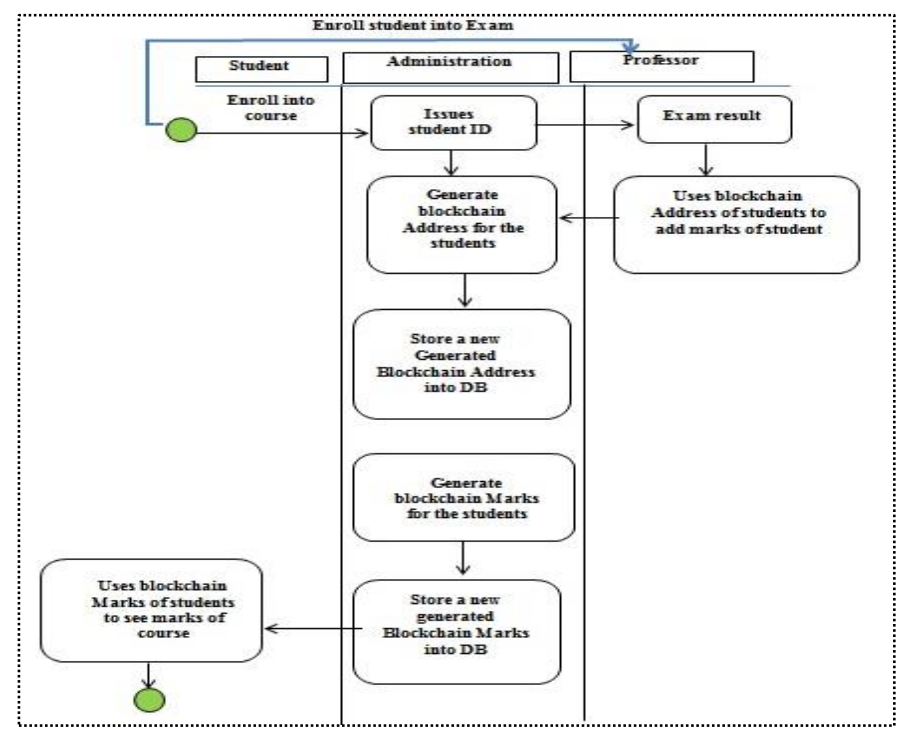

Figure.7 Diagramof Student's marks \& information

After students register in the all desired courses, the data of students will be submitted to the control committee. After the registrationprocess, the profile student will be create by enrolled his into listing all the courses. After registration, all parties concerned can access the new student. Each student will have personal unit of transactions (ID, courses, MidTerm mark, Coursework mark, Final exam.). The transferred information is stored on the blockchain. Administration must upload student records (student information) and store over the blockchain network.

All of the transaction of model are validated and no changeable it.Figure 8 shows all the student transactions in the university. Therefore the manipulation is decreases. The university employer input student information data and a unique hash is taken from database then adds it to the blockchain. 
The administration of the university stores information (Student ID, Username, registration course of the student) into its centralized database.

All students have unique username and password to access the model and mange his account. As we can see from the previous section, everymodel has its strengths and weakness; we review this in the table

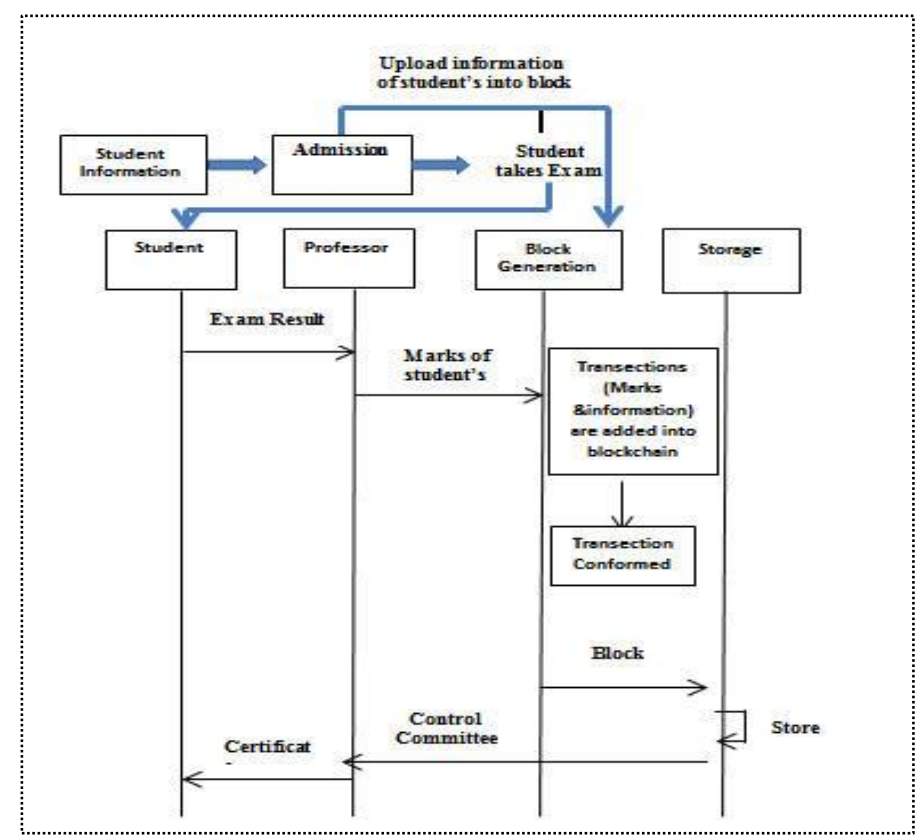

Figure.8Diagram for storing blocks of marks in blockchain

Table1: Comparing of three models

\begin{tabular}{|c|c|c|c|}
\hline$\frac{\text { Feature }}{\underline{\mathbf{s}}}$ & $\underline{\text { Model } 1}$ & $\underline{\text { Model2 }}$ & $\underline{\text { Model3 }}$ \\
\hline $\begin{array}{l}\text { Network } \\
\text { size }\end{array}$ & $\begin{array}{c}\text { One } \\
\text { blockchain } \\
\text { supply } \\
\text { demand } \\
\text { networks } \\
\end{array}$ & $\begin{array}{c}\text { multi- } \\
\text { blockchains } \\
\text { supply demand } \\
\text { networks }\end{array}$ & $\begin{array}{c}\text { One } \\
\text { blockchain } \\
\text { supply demand } \\
\text { networks }\end{array}$ \\
\hline $\begin{array}{l}\text { perform } \\
\text { ance }\end{array}$ & $\begin{array}{l}\text { Improving } \\
\text { the model } \\
\text { cycle time } \\
\text { decrease } \\
\text { order updates. }\end{array}$ & $\begin{array}{c}\text { more } \\
\text { confirmation } \\
\text { time because } \\
\text { more number of } \\
\text { block }\end{array}$ & $\begin{array}{l}\text { Storage data } \\
\text { in one record as } \\
\text { "one data" } \\
\text { Changing the } \\
\text { block } \\
\text { continuously in } \\
\text { real time. }\end{array}$ \\
\hline Security & $\begin{array}{c}\text { Flexible } \\
\text { and secure } \\
\text { because of } \\
\text { their storage } \\
\text { data is limited } \\
\text { so the data is } \\
\text { more reliable. }\end{array}$ & $\begin{array}{c}\text { verified each } \\
\text { transaction } \\
\text { data is } \\
\text { reliable }\end{array}$ & $\begin{array}{c}\text { storage } \\
\text { capacity } \\
\text { resilient, } \\
\text { flexible and } \\
\text { secure } \\
\text { Resource } \\
\text { sharing on a } \\
\text { public. }\end{array}$ \\
\hline
\end{tabular}




\section{Conclusion}

Our models add more security via the use of hashing and data readily available with decentralized data storage. The student data can be stored by building three models based on blockchain. Using Blockchain, we designed of three blockchain models. The infrastructure of models are based on blockchains are well suited for large-scale data processing.

Universities can deal with student management system (SMS) in a way that greatly achieves security. Storing and sharing data will be simpler with decentralized data storage and could be programmed into the blockchain. Another feature the ledger can represent as valid guide to maintain student management system (SMS) and introduces reliable, highly trusted model for accessing and storing data.

\section{References}

1. V. A. Tolbatov, 'USING BLOCKCHAIN TECHNOLOGY FOR E-LEARNING', " Вимірювальна та обчислювальна техніка в технологічних прочесах, vol. 61, no. 1, pp. 110-113, 2018.

2. F. O. Ezeudu, N. M. Eya, and H. I. Nworgi, 'Application of Blockchain-based Technology in Chemistry Education Students ' Data Management', Int. J. Database Theory Appl., vol. 11, no. 2, pp. 11-22, 2018.

3. K. Palanivel, 'Blockchain Architecture to Higher Education Systems', Int. J. Latest Technol. Eng. Manag. Appl. Sci. , vol. VIII, no. Ii, pp. 124-138, 2019.

4. K. Salah and N. Nizamuddin, 'Blockchain for AI : Review and Open', no. December, 2018.

5. Y. U. Chandra, S. Surjandy, E. Fernando, and H. Prabowo, 'DEFYING THE CERTIFICATION DIPLOMA FORGERY WITH BLOCKCHAIN PLATFORM : A PROPOSED MODEL DEFYING THE CERTIFICATION DIPLOMA FORGERY WITH BLOCKCHAIN PLATFORM : A PROPOSED MODEL', no. July, 2019, doi: 10.33965/ict2019.

6. S. M. K. V. P. Kumar, K. K. Kumar, R. S. Krishna, and P. S. G. A. Sri, 'Incorporation of Blockchain in Student Management System’, Int. J. Innov. Technol. Explor. Eng., vol. 8, no. 6, pp. 664-668, 2019.

7. V. Juričić, M. Radošević, and E. Fuzul, 'Creating student' s profile using blockchain technology', 2019 42nd Int. Conv. Inf. Commun. Technol. Electron. Microelectron., pp. 521-525, 2019.

8. M. Torky, T. Gaber, and A. E. Hassanien, 'Blockchain in Space Industry - Challenges and Solutions-', arXiv Prepr. arXiv2002.12878.2014,.

9. Okanya, A. ., Asogwa, J., \& Onyedikachi, I. . . (2021). Indoor Environmental Quality (IEQ) in Nigerian Tertiary Institutions: The Effect on Performance of Building Technology Lecturers. Middle Eastern Journal of Research in Education and Social Sciences, 2(1), 172-186. https://doi.org/10.47631/mejress.v2i1.143

10. D. Tapscott and A. Tapscott, 'THE BLOCKCHAIN REVOLUTION \& Higher Education.', vol. 52, no. 2, pp. 2017, [Online]. 24, Available: http://widgets.ebscohost.com/prod/customerspecific/ns000290/authentication/index.php?url=https\%3A\%2F \%2Fsearch.ebscohost.com\%2Flogin.aspx\%3Fdirect\%3Dtrue\%26AuthType\%3Dip\%2Ccookie\%2Cshib\%2 Cuid\%26db\%3Da9h\%26AN\%3D122453203\%26amp\%3Blang\%3Dpt-pt\%26site\%3Deds-li.

11. A. I. B. M. Han, Z. Li , J. He , D. Wu , Y.Xie, 'A Novel Blockchain-based Education Records Verification Solution', in (In Proceedings of the 19th Annual SIG Conference on Information Technology Education ,2018, pp. 178-183.

12. [Anggraeny, A. S. . (2020). The Effect of Implementing the Financial Management Information System on the Quality of the Presentation of the Pangkep Regency Government's Financial Statements. Journal of Advanced Research in Economics and Administrative Sciences, 1(1), 32-44. https://doi.org/10.47631/jareas.v1i1.17

13. H. Al Breiki, L. Al Qassem, K. Salah, M. Habib Ur Rehman, and D. Sevtinovic, 'Decentralized access control for IoT data using blockchain and trusted oracles', Proc. - IEEE Int. Conf. Ind. Internet Cloud, ICII 2019, pp. 248-257, 2019, doi: 10.1109/ICII.2019.00051. 